\title{
Literary Comprehension through Mother Tongue and the Achievement of Grade 3 Pupils in One District Public Schools
}

\author{
Rowena G. Bolado ${ }^{\mathrm{a}}$, Randy L. Palestina ${ }^{\mathrm{b} *}$ \\ a rowena.bolado@deped.gov.ph \\ ${ }^{a}$ Bugtong na Pulo Elementary School, Lipa City 4217, Philippines \\ ${ }^{b}$ De La Salle Lipa, Lipa City 4217, Philippines
}

\begin{abstract}
The development of the learner's academic performance begins with the clear understanding and comprehension of underlying concepts and ideas. Learners who find difficulty in reading comprehension tend to manifest poor academic performance. In addition, the language used in the materials or articles influences the learner's level of comprehension. Hence, this study investigated the literary comprehension through Mother Tongue and the achievement of Grade 3 pupils in the North District, Division of Lipa City. The respondents were 287 Grade 3 pupils in the selected schools in the North District particularly from Senator Maria Kalaw Katigbak Memorial School, Teodoro M. Kalaw Elementary School, Abundio Torre Elementary School, Dagatan Elementary School, and Inosluban-Marawoy Elementary School. Using quantitative correlational design as a descriptive research, the literary comprehension through Mother Tongue such as poems, short stories, riddles, parables, fables, and legends and the pupils' achievement in the following assessment tools; PHIL-IRI, Quarterly Assessment, and grades in the Report Cards were explored in the study and investigated to find the relationships. Findings revealed that the level of comprehension of the learners when the material is expressed in Mother Tongue is significantly related to the academic performance in terms of the PHIL-IRI, Quarterly assessment score, and the grades in the Report Cards. The Grade 3 pupils comprehend in a very satisfactory level in the literary genres because they are written and presented in their mother tongue. The pupils' gained very satisfactory level of achievement in terms of poems, short stories, riddles, parables, legends and satisfactory level of comprehension in fables.
\end{abstract}

Keywords: academic performance; Mother Tongue; reading comprehension; literary comprehension

\section{Introduction}

The educational system of the Philippines has been transformed to K to 12 Enhanced Basic Education Curriculum enhancing the Philippine Basic Education in accordance with the Republic Act 10533 which was released on May 15, 2013. Republic Act No. 10533 is a law that implements K to 12 Program, which covers kindergarten and 12 years of basic education. The enhanced basic curriculum aims to produce Filipino graduates who are holistically developed with 21 st century skills. This curriculum also gives a great chance to all graduates to acquire middle-level skills for better work opportunities. Under Republic Act No. 10533, mother tongue 
language is the language of instruction from kindergarten to Grade 3 to attain mastery of learning competencies. On the other hand, starting Grade 4 to Grade 6, teachers will use English and Filipino as their medium of instruction. Enhance Basic Education Act of 2013 is final. Department of Education and the whole nation came across the gigantic challenge in our educational system. In this new system, Kindergarten is compulsory, which means that before the students can enroll in Grade 1, it is a must for them to undertake kindergarten. The number of years in elementary are the same; however, there are two divisions in high school - four years in junior high school and two years in senior high school. One of the changes in Enhanced Basic Education Curriculum brought about by the new K-12 program was the introduction of Mother-Tongue Based Multilingual Education (MTB-MLE) specifically in kindergarten, Grades 1, 2 and 3 to support the goal of Every Child- A Reader and A- Writer" by Grade 1.

This program is spelled out in the DepEd Order No. 16 Series of 2012 with the key objectives that follow: first that the language development must establish a strong education for success in school and for lifelong learning; secondly, that the cognitive development focuses on Higher Order Thinking Skills (HOTS); then, the Academic development prepares the learner to acquire mastery of competencies in each of the learning areas; and lastly, the Socio-cultural awareness enhanced the pride of the learner's heritage, language and culture. Mother-Tongue Based Multilingual Education (MTB-MLE) refers to first language-first education that is, schooling which begins in the Mother Tongue and transitions to additional languages particularly Filipino and English. L1 refers to the Mother Tongue, L2 refers to Filipino, and L3 refers to English. The goal of MTBMLE is to address the high functional illiteracy of Filipinos where language plays a significant role.

In accordance with this goal the learning materials like the small book and the big book are so vital in MTB-MLE because through these materials they were encouraged to read stories or any literary genres that enriched not just their vocabularies but as well as their experiences, traditions, and culture as well.

The study focused on one of the districts in Lipa City. This is due to the reason that in spite of the positive perceptions on the use of Mother Tongue based on day-to-day implementation, several problems were identified. One of these problems was the numerous numbers of readers both in Filipino and English under "Frustration Category;" as revealed by the PHIL-IRI results. This means that pupils weren't able to answer the questions about the literary genres. Only a few got fall into instructional readers which mean that they have moderate reading and comprehending skills. Furthermore, very rare fell under independent readers who have the ability to answer almost the seven questions within a very short period of time.

PHIL-IRI which means Philippine Informal Reading Inventory assesses the reading proficiency levels, including word recognition, comprehension, and reading speed of elementary pupils. They still have reading incapacity in spite of using the language familiar to them. Due to this reason they failed to get the correct responses to the given questions. Even worst is that they don't even comprehend simple words written and translated in English.

In this case, they would not be able to comprehend idiomatic expressions, short stories and poems even written in vernacular. Furthermore, in spite of the high grading system (DepEd Order no. 8 Series of 2015) poor academic performance, especially for the below average pupils became evident and this was seen on their report card and the worst to the National Achievement Test of Grade 3 also known as the Language Assessment Test for Primary Grades. Moreover, the compulsory use of Lingua Franca in educational system greatly affects the development and competence of the English language among learners which is vital in order to compete globally.

This seemed to be off tangent in DepEd mission and vision. When learners at their young age are trained with the use of the pure Mother Tongue, how could they be proficient for the literary genres waiting for them in the intermediate years where almost all subjects are taught using the English Language? This study was necessary to explore in order to inform the parents, teachers, stakeholders and the community itself the benefits and effectiveness of the use of MTB-MLE as a medium of instruction in the primary grades especially in Grade 3. 
In addition, the study opened up the minds of the parents about their vital role in educating and nurturing their siblings; that they must strive hard and cooperate well with the teachers to make quality education and effective learning happen. Finally, the results of this study greatly affect the context/role of a teacher in a way that they'll be very much careful enriching their instructions in putting emphasis on using Mother Tongue but at the same time allowing their pupils to be more acquainted and familiar, not just in their lingua franca but as well as to the English language for them to be more comfortable with their upcoming intermediate grades.

\subsection{Theoretical Framework}

The language theories from which this study was hinged are: Behavioral Theory, Cognitive Theory, Nativist Perspective Theory, Social Interactionist Theory, and Ricento and Hornberger's Language Planning and Policy Model (1946).

Behavioral Theory by B.F. Skinner (1956) posited language is something that can be observed and measured. The need to use language is stimulated and language is uttered in response to stimuli. Competence in the rules of language is not as important as the ability to speak it; speaking is what makes language real. Knowledge is a mental state and the function of speaking words that makes a language a language.

Cognitive Theory by Jean Piaget (1936) cites that language is made up of symbols and structures but exhibits itself as a child's mental abilities mature. In addition, language is only one of many human or cognitive activities. How children's minds work and develop has been enormously influential, particularly in educational theory. It says that the role of maturation (simply growing up) in children's increasing capacity to understand the world: they cannot undertake certain tasks until they psychologically mature enough to do so.

Nativist Perspective Theory by Noam Chomsky states that infants have an innate ability to learn language. From a very early age, they able to understand the basics of language and the children are able to understand the appropriate order of words at young ages. He pointed out that all humans have a language acquisition device (LAD). The Lad contains knowledge of grammatical rules common to all languages and allows children to understand the rules of whatever language they are listening to.

Social Interactionist Theory by Lev Vygotsky stresses that environment and the context in which the language is being learned. In this theory, the beginning speaker and the experienced speaker-be they child and adult or second-language learner and fluent speaker -exist in a negotiated arrangement where feedback is always possible. Thus, its basic appeal is the importance of places on the home and the cultural environment in early-childhood language acquisition.

The study was also anchored on Ricento and Hornberger's Language Planning and Policy Model (LPP) (1946) a theory that considers the different actors within each of the national, institutional, and interpersonal levels. In this study, the national level refers to the language policy statements which commanded us to make Mother Tongue as a medium of instructions in the primary grades up to grade three to improve the learning outcomes and promoting Education for All (DO. No. 74, s. 2009). The institutional level refers to parents as actors in the community. Since the pupils are always in contact with their families and communicate with them most of the time in the medium both familiar to both of them. Hence, the interpersonal level refers to teachers as actors in the classroom. The pupils stay in the school for almost eight long hours every day, discussing and communicating through the use of Mother Tongue.

An examination of each level of model highlights how reform implementation approaches from the national, institutional and interpersonal level interact to influence implementation and comprehension towards the literary achievement and outstanding performance of the pupils at the classroom level having Mother Tongue as the primary key and guidelines. These interactions, conditions of language acquisition and implementation were discussed, explained and guided by the language theories mentioned above.

Furthermore, these theories were explained, and proven true by the present study wherein all subjects in the primary grades specifically grade 3 were thought in their mother tongue except for English and Filipino. 
This shows how effective and how the pupils' learning lasts not only if the above institutions work harmoniously but also if they work collaboratively.

\subsection{Conceptual Framework}

Figure 1 shows the IPO Model used and visualized by the researcher in order to achieve the desired result of the study. It contains the INPUT, PROCESS, and the OUTPUT of the present study.

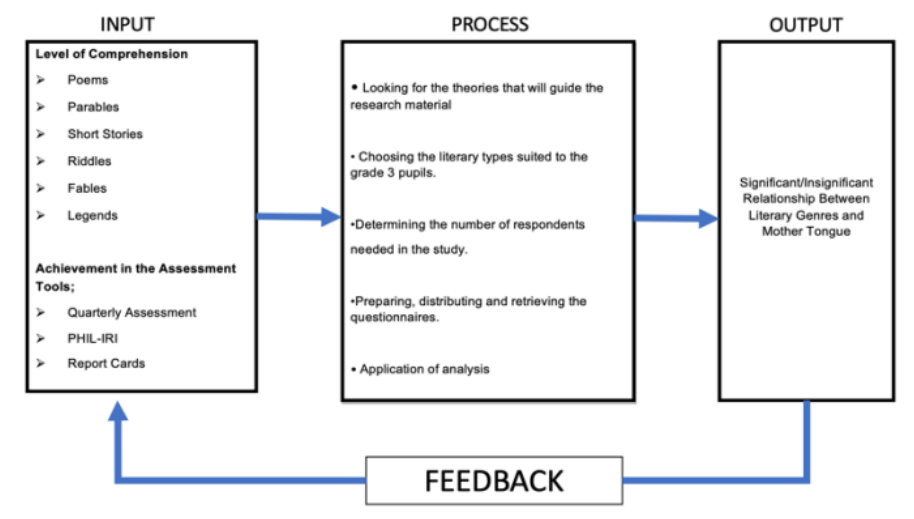

Fig. 1. Conceptual Framework of the Study

In the research paradigm, the IPO Model was used. The first box indicates the INPUT of the study. This includes the Mother Tongue level of comprehension of the students in the following literary genres, namely, poems, short stories, essays, riddles, and fables. It also includes the achievement of the pupils through the use of the following records and assessment tools; report cards, quarterly test, quarterly assessment and PHIL-IRI. This will be explained and supported by the statistical tools in which this study intended to use.

The second box is composed of the PROCESS of looking for the theories that will guide the research material; choosing the literary types suited to the Grade 3 pupils; determining the number of respondents needed in the study and at the same type the size of the population enough to represent the North District; and lastly the preparation, distribution and retrieval of the questionnaires. However, in order to measure their achievement; the different assessment tools and records were requested, compiled, and interpreted. Through the abovementioned process, the OUTPUT of the study will be formulated. The end result will be the Significant/Insignificant Relationship Between Literary Genres and Mother Tongue.

\subsection{Statement of the Problem}

This study determined the impact of Mother-Tongue on Comprehension and the literary achievement of Grade III pupils in the selected schools in the North District. Specifically, the study answered the following questions:

1. What is the level of comprehension of the Grade 3 pupils in the following literary genres?

1.2 Poems;

1.3 Short stories; 
1.3 Riddles;

1.4 Parables;

1.5 Fables; and,

1.6 Legends?

2. What is the achievement of the grade III pupils in the following assessment tools integrating Mother Tongue as medium of instruction?

2.1 PHIL-IRI;

2.2 Quarterly Assessment; and,

2.3 Report Cards;

3. Is there a relationship between the level of comprehension and in the literary achievement of grade 3 pupils?

\subsection{Scope and Limitation}

This study focused on the Literary Comprehension through Mother Tongue and Achievement of Grade 3 pupils in the selected schools in the North District. The said selected schools got the lowest rank on the previous Language Assessment Test for Primary Grades (LAPG) as seen on Institutional Result of the LAPG (Lipa City) for the SY. 2014 - 2015. The students were the only respondents of the study because the study wanted to know the comprehension level and the relationship of using Mother Tongue and the achievement. The respondents of the study were delimited to 287 only due to financial scarcity, the time, the study ran. The size of the school and above all for the safety of the researcher for some of the schools are too far. It also emphasized the literary comprehension of pupils and delimited to the following literary genres, namely, poems, short stories, parables, riddles, fables, and legends. This study was delimited to use three literary pieces written in their own Mother Tongue because of the limitations on time, financial and resources covered by this study.

\subsection{Significance of the Study}

The study posits its significance to the following:

Pupils. They will directly benefit because through this study, the teachers, and the curriculum designer will give a lot emphasis on the use of Mother Tongue in enriching the knowledge and appreciation of the pupils in the literary genres, where they can also learn valuable lessons.

Teachers. This study will identify the strengths and weaknesses of the instruction and curriculum. This modification will be incorporated.

School Heads. This will give them enough insights on what INSET trainings, workshop, seminars, they are going to employ in order to enhance and uplift the literary proficiency of their teachers for effective learning to happen because the result of the study is a living proof that Mother Tongue enriches the knowledge and understanding of these literary genres.

Parents, Community and Stakeholders. This study will make them realized to give their siblings/offspring long time allotment for their study habits for them to read and comprehend the literary genres.

Curriculum Planners/Writers. They could gain productive insights on how are they going to design, where and what to base the curriculum in order not just to enrich one's own language but as well as the second language in order to assure that their target learners are really not left behind globally and at the same time the masters of their Mother Tongue especially in the different literary genres.

Future Researchers. From this study, the findings and conclusions will serve as bases, and insights on how the lingua franca and the efficient instructional supervision and skills of the teachers can produce a quality, globally competitive pupils in the near future. 


\subsection{Definition of Terms}

For clarity, the following terms that are used in this study were given the corresponding conceptual and operational definitions:

Literary comprehension. It refers to the scores gained by the teacher - made literary test which content includes genres such as poems, short stories, legends, parables, fables, and riddles as well as in reading and writing.

Poems. In this study, these refer to the compositions in verse; pieces of literary genres that are written on separate lines that often have repeated rhythm and oftentimes rhyme.

Short Stories. Refer to brief works of fiction, usually written in prose and can be found in oral storytelling that have limited numbers of words and teach valuable lessons in life.

Legends. These pertain to non-historical or unverifiable stories handed down by tradition from earlier and popularly accepted as historical and stories which are not always true.

Parables. These refer to the stories coming from the Bible from which the students can learn valuable lessons

Fables. These refer to stories, typically with animals as characters, conveying a moral that passed down from generation to generation and told to teach a lesson.

Riddles. In this study, these pertain to questions or statements intentionally phrased so as to require ingenuity in ascertaining its answer or meaning presented as a game

Achievement. In this study, it refers to the scores gained by the students based on the PHIL-IRI, Quarterly Assessment, and Report Cards through Mother Tongue.

Mother Tongue - Based Multilingual Education (MTB-MLE). In this study, it refers to the Language used in the instruction of the literary genre which gives a clear view that L1 refers to the Mother Tongue, L2 is Filipino, and L3 pertains to English language.

Comprehension. In this study it measures the pupils' level of understanding and consumption of the literary genres written, expressed, and translated in their own Mother Tongue.

PHIL-IRI. It is the acronym for Phil. Informal reading Inventory which is an initiative of the Bureau of Elementary Education which is anchored on the flagship program of DepEd "Every Child A Reader Program. The goal of which is to enable every Filipino to communicate proficiency both in English and Filipino through effective reading instruction.

LAPG. This Language Assessment Test for Primary Grades (NAT before) as the term suggests, evaluate the effectiveness of the Mother Tongue Based-Multilingual Education to the teaching and learning process in the primary grades.

Assessment Tools. In this study, this pertains to the records to be requested from the respondents of the study, namely; report cards, quarterly assessment, and PHIL-IRI Results.

\section{Review of Related Literature and Studies}

This section presents vital information inherent in different books, general references, journals and magazines, published and unpublished studies, case study, thesis and dissertation, and related literatures reviewed by the researcher, which are deemed closely related to the present study. These are shown and discussed by topic/theme.

\subsection{Definition of Mother Tongue}

Mother Tongue as a first language (also native language, father language/mother tongue, arterial language, or L1) is a language that a person has been exposed to, from birth or within the critical period. In some countries, the term native language or mother tongue refers to the language of one's ethnic group rather 
than one's first language.

Mother Tongue is typically the first language of the child and the language of the home. It can also be construed as the language of primary socialization, the language developed by a child from an early childhood. Mother Tongue education implies a linguistically homogeneous community, a teacher who speaks the language, and the curriculum materials in the mother tongue.

The Asia-Pacific region is characterized by rich ethnic, cultural, and linguistic diversity. As in other parts of the world, human diversity is a natural phenomenon, but imperialist and/or colonial processes have imposed dominant group languages or language varieties over prevalent regional ones. In some areas, people's mother tongues are systematically ignored.

As a result, the true linguistic panorama of a national population is rarely reflected in its school system, and large numbers of learners are confronted with either a foreign medium of instruction or a language variety that does not match their own (see Kosonen, 2005).

Making educational opportunities more equitable means dealing explicitly with children of disadvantaged groups through affirmative measures such measures should improve their chances to access school and remain there long enough to benefit socially, economically and in every other way that reduces their vulnerability.

Understanding the conditions under which marginalized populations live is a crucial first step towards designing a school system that works on their behalf, rather than holding them to standards that only the elite can hope to meet - standards that reproduce inequality.

Language and education are closely related. Since language is a main means of human communication, almost all educational activities, including literacy, use language in some way.

In multilingual settings, decisions about the relationship between language and education are not straightforward and never easy. Instead, serious consideration is needed to determine which languages to use in education and literacy programs.

Learners having insufficient comprehension and command of the languages used as the languages of literacy and languages of instruction are likely to learn differently from those fully proficient in the languages used. This usually includes ethno-linguistic minorities in multilingual settings.

In some cases, people speaking languages with millions of speakers also have to study through a language in which they may not be proficient. Most Asian nations are linguistically diverse, and thus the language issue is important across the region.

The shift in language policy is part of a growing trend around the world to support mother tongue instruction in the early years of a child's education. In Southeast Asia, this is apparent in a rising number of educational programs that utilize a mother tongue approach.

While the use of non-dominant languages in education is allowed in countries such as Cambodia, Indonesia, Malaysia, Vietnam and Thailand, the Philippines is the single country to institute a national policy requiring their inclusion in the early grades.

As a result, the implementation of MTB-MLE in the Philippines is being looked at as an example for the rest of the region.

As envisioned by the Education for All (EFA) program and the Millennium Development Goal (MDG), countries around the world, especially the developing ones like the Philippines, are provided with both financial and technical assistance from international development agencies.

The countries have also attempted various policy changes to ensure access, equity, quality and relevance of primary education. One of the policy level innovations we can see is the introduction of learners' mother tongues in schools, both as a subject and the medium of instruction.

Various studies (e.g. Benson, 2002; Dutcher, 2003) have identified those children's' overall educational attainment can be enhanced if they are taught in their mother tongue in the early grades. 
In contrary to this, teaching in a dominant language, which is different from children's mother tongue, in early grades invites serious challenges in education, e.g. high drop-out rates, low educational attainment and lack of classroom interaction (UNESCO, 2003).

Due to these problems, as reported by Dutcher (2004), a large number of indigenous children, who come from different linguistic groups, are still out of school, and even if they have joined the school they are marred with the low performance on the ground of their low competence in the dominant language (s) which is used as the medium of instruction in schools.

With MTB-MLE comes the growing apprehension from the teachers that teaching in a mother tonguebased program requires a vastly different set of skills, many of which they apparently do not have at the moment. The teachers are particularly concerned with practical issues such as producing homegrown and contextually sensitive teaching and reading materials, and how to actually develop greater fluency in their own languages.

The broad categories of materials needed to implement an MTB-MLE curriculum includes early literacy materials in the mother tongue, a variety of on-grade narrative reading materials using the mother tongue, possibly subject-area materials in the mother tongue, materials to transition from the mother tongue into the second language, and then, of course, materials as appropriate for the educational system in the second language.

In most cases, appropriate mother tongue materials will be lacking and will need to be prepared. Other educational materials in the mother tongue will likewise have to be constructed by those proficient in writing the language and with appropriate educational backgrounds or experience in constructing learning materials.

Likely the most technically demanding skills will be needed to structure the primary literacy materials, since effective materials will require knowledge of how to present the symbol-to-sound rules and the sound-tomeaning conventions for writing the language in a way that aligns with the students' capabilities.

In the Philippines, the Mother Tongue-Based Multilingual Education (MTB-MLE) is implemented sometime in 2014. It is a formal or non-formal education which uses the child's mother tongue as a bridge in learning Filipino and English. Using the language they understand, the children develop a strong foundation in their mother language.

MTB-MLE is a structured program of language learning and cognitive development that provides learners with a strong educational foundation in the first language. A strong foundation in the use of the mother tongue is required for learning a second language. The children's understanding of concepts is limited or confused if learning is only done with the use of the second language.

Mother tongue is the language that a person learns in the society he/she lives especially from his/her mother by imitating herself which begins from the period of infancy and also mother tongue is the language that he/she expresses him/herself best. Vardar (1980:20) defines mother tongue as, "Mother tongue is the language which is learned for the first time within the family or the society that a person he/she lives".

According to Aksan (1990:81), Mother tongue is the language which is learned from mother and close relatives at first, and then within the society that a person he/she lives and that is present at the subconscious level and establishes a strong connection between the person and the society he/she lives.

Some linguists define mother tongue briefly as "the language learned from mother" considering the word "mother" that exists within the structure of the term of mother tongue.

Tochon (2009) said Mother Tongue Education (MTE) is also referred to as a first language, mother tongue medium education, or mother tongue instruction.

In strong multilingual education program, the learners' first language is used as the language of instruction as long as possible, at least at the pre-primary and primary levels.

\subsection{Importance of Mother Tongue to Learning}

Findings (British Council) consistently show that learners benefit from using their home language in education in early grade years. The learners benefit from using their home language in education in early grade years (ahead of a late primary transition stage). 
Using the mother tongue in early education leads to a better understanding of the curriculum content and to a more positive attitude towards school and the kids do better when taught in their mother tongue. By means of using the learners' home language, learners are more likely to engage in the learning process. The interactive learner-centered approach - recommended by all educators - thrives in an environment where learners are sufficiently proficient in the language of instruction. It allows learners to make suggestions, ask questions, answer questions and create and communicate new knowledge with enthusiasm.

It gives learners confidence and helps to affirm their cultural identity. This in turn has a positive impact on the way learners see the relevance of school to their lives. A crucial learning aim in the early years of education is the development of basic literacy skills: reading, writing and arithmetic. These skills build on the foundation and interaction skills of speaking and listening. When learners speak or understand the language used to instruct them, they develop reading and writing skills faster and in a more meaningful way.

In summary, the use of learners' home language in the classroom promotes a smooth transition between home and school. It means learners get more involved in the learning process and speeds up the development of basic literacy skills. It also enables more flexibility, innovation and creativity in teacher preparation.

Using learners' home language is also more likely to get the support of the general community in the teaching/learning process and creates an emotional stability which translates to cognitive stability. In short, it leads to a better educational outcome. Initially other languages are taught as the second language using appropriate methodologies of second-language learning. At higher grades, both languages would be used as the languages of instruction and literacy, as well as

studied as subjects. It is essential that the use of the first language continues throughout the education system.

Likewise, equally important is that the second language is introduced gradually before it becomes a language of instruction. The same principles also apply to education and literacy. The bottom line is that learning is started with and through something that the learners already know, i.e. their first language, and unfamiliar things, such as the second language, are introduced gradually and learned after a solid foundation in the first language has already been accomplished.

International research shows that at least some five years of instruction in the first language - but preferably throughout the education system - is required to provide a solid foundation for further studies (Baker, 2006; Baker \& Hornberger, 2001; Benson, 2004, 2005; Cummins, 2000, 2001; Thomas \& Collier, 2002).

Once the child uses his/her own language, his/her ability to communicate develops and this enables his/her to explore the environment and, in the process, acquire literacy (Kuntze, Golos \& Enns, 2014; Svartholm, 2010). According to Cummins (1991) a well-developed first language is the springboard to the acquisition of a second language. This implies therefore, that students who use their first language are proficient in it are more likely to develop literacy.

Literacy has gained much importance in literacy education in the western countries in the past few decades (Behrman; 2006; Ko \& Wang, 2009). Therefore, to be literate in the contemporary society requires not merely the ability to read and write but a critical mind to see through the assumptions or positions hidden in the text written in their own language (McLaughin \& DeVoogd, 2004) their own language (McLaughin \& DeVoogd, 2004)

Proficiency as viewed by Harste and Freire (2003) from this expanded perspective which is not longer concerned simply with isolated skills, but deals with diverse social practices that have an enormous impact on our understanding of literacy.

\subsection{Relationship of Proficient and Literacy}

Studies have provided ample evidence that the pupils who are proficient in their own Mother Tongue achieved valuable and worthwhile activity. These achievements involve reading and comprehending literary genres, language comprehension and expressive language skills (Gest, Freeman, Domitrovich and Welsh, 
2004), but also on attitudes towards attentiveness in the classroom (Rowe, 1991).

These studies suggest that literacy and being proficient have a significant relationship. That one they were proficient in the language they are using literacy came next, but if they were not they failed to do so. Sidwell Tshingilane (2015) stated that Kids do better when taught $\mathrm{n}$ their mother tongue. The reason why some black learners and students fail or do not do well is because they are taught all subjects in foreign languages. English and Africans-speaking students have an advantage because they write their exams in their native languages.

In addition to those mentioned statements above were the importances of mother tongue proficiency to the understanding of literary genres described and explained below. Tomasulo and Pawelski (2012) cited that parables are didactic stories that were initially composed and orally transmitted to teach a pertinent life lesson and to guide children on how to live a morally upstanding life through God's words and teachings.

Paris (2003) has demonstrated that children develop riddles schema through repeated exposure to riddles. These riddles employ a guessing game structure that leads to an intention of arriving to the correct answer. Rog (2001) stated that reading the stories mean to develop children's concepts about print, story structure, and other elements of text and provides the child with a wealth of information about the processes and functions of written language.

On the other hand, Needlman (2004) asserted that the teacher must uses strategy in order for the pupils to well comprehend the short stories like reading aloud. There are many reasons to read aloud to students. These include 1.) Reading aloud is fun; 2.) Reading aloud keeps interest high; 3.) Reading aloud builds listening skills; 4.) Reading aloud builds vocabulary and lastly; 5.) Stories are the building blocks of imagination.

Gold and Gibson also emphasized that reading aloud is the foundation of literacy development and that it demonstrates the relationship between the printed word and meaning and invites the listener into conversation with the author.

\subsection{Relationship of Achievement and Literacy}

Mother Tongue-Based Teaching and Education for students highlights in more detail the correlations between students, language and marginality, and show that there are indeed positive links between the use of mother tongue in education and their participation and achievement in learning.

While many challenges remain, the use of mother tongue in education has powerful pedagogical and social justifications and, thus, is a critical step in the right direction towards achieving Education for All.

More pupils enrol in school when they can learn in a language that is familiar to them. Pupils and their families may be less apprehensive about attending a school that uses their language and, by association, a familiar culture and set of values.

Teachers in a bilingual program speak to students and their families in the L1, increasing family access to information about enrolment and schooling

processes. School use of the home language increases parent participation and influence.

Improved communication allows parents to participate in school activities and decision-making, so that schools respond more to community needs and values. The resulting curriculum may better meet local needs, so that schooling becomes more relevant and productive for the pupils.

Girls in bilingual classes stay in school longer. Mother tongue-based schooling makes the home-school transition easier. Since girls have less exposure to the second language, they feel more comfortable speaking and learning in the L1. They are more likely to enjoy school and perceive that schooling is relevant when they experience success, which will promote achievement, as well as the confidence to continue their school careers.

\subsection{Dep-Ed Memo Regarding the Use of Mother Tongue}

In the Philippines, the Department of Education issued DO No. 74, s. 2009 Institutionalizing Mother 
Tongue Based-Multilingual Education (MTB-MLE) in the country. This was strengthened by the declaration of the President of the Philippines Benigno Aquino, Jr. when he said:

Learn English well and connect to the world.

Learn Filipino well and connect to your country.

Retain your dialect and connect to your heritage.

According to DepED Order no. 74, s. 2009, MTB-MLE is the effective use of more than two languages for literacy and instruction which also established a framework that provides curricular guidance of teachers, school managers, instructional quality assurance for teachers and other educational leaders.

DO No. 6 s. 2012 emphasizes L1-L2-L1 or L2-L1-L2 as a guide in the use of the Mother Tongue. This means that Mother Tongue referred as L1 shall be used as the MOI and L2 as Filipino subject. Based on the Dep-Ed Order No. 16, s. 2012 also known as, "The Guidelines of the Implementation of Mother Tongue-Based Multilingual Education (MTB-MLE) states that starting School Year (SY) 2012-2013, the MTB-MLE Education shall be implemented in all public schools, specifically in Kindergarten, Grades 1, 2 and 3 as part of the K to 12 Basic Education Program.

DO No. 28 s. 2013 is an additional guideline to Dep-Ed Order No. 16, s. 2012, which states that the following languages, namely; Ybanag, Ivatan, Sambal, Akianon, Kinaray-a, Yakan and Surigaonon shall be used as the languages of instruction for Grade 1 pupils who speak the same languages. These languages will used in the specified regions and divisions starting school year (SY) 2013-2014. RA 10533 also mandates the use of Mother - Tongue Based Multilingual Education (MTB-MLE). Since June 2013, DepEd has supported 19 languages that cater to our diverse set of students and learners. These languages include Bahasa Sug, Bikol, Cebuano, Chabacano, Hiligaynon, Iloko, Kapampangan, Maguindanaoan, Maranao, Pangasinense, Tagalog, Waray, Ybanag, Ivatan, Sambal, Akianon, Kinaray-a, Yakan, and Surigaonon.

\subsection{Relationship of Proficiency and Literacy}

Studies have provided ample evidence that the pupils who are proficient in their own Mother Tongue achieved valuable and worthwhile activity. These

achievements involve reading and comprehending literary genres, language comprehension and expressive language skills (Gest, Freeman, Domitrovich and Welsh, 2004), but also on attitudes towards attentiveness in the classroom (Rowe, 1991).

Rog (2001) noted that comprehension of stories means to develop children's concepts about the print, story structure, and other elements of text and provides the child with a wealth of information about the processes and functions of the written language. Aside from that, the teacher must use strategies that will arouse the students' curiosity and attentiveness to the short stories like reading aloud to them. As asserted by Needlman (2004) that there are many reasons to read aloud to students like reading is together is fun, that it keeps interest high, and

that it builds listening skills and vocabulary and the building blocks of imagination.

In addition to what they said Gold and Gibson (2001) cited that reading aloud is the foundation of literacy development and that it demonstrates the relationship between the printed word and meaning and invites the listener into a conversation with the author that will lead to productive output. However, in terms of riddles, reading comprehension as noted by Paris (2003), children develop riddles schema through repeated exposure to the riddles; employing a guessing game structure that leads to an intention to achieve a goal that proposed the ability to use, identify, organize and understand information from the text in order to arrive at the correct answer.

Parables comprehension as cited by Tomasulo and Pawelski (2012) teach a pertinent life lesson and that these guide children on how to live a morally upstanding life through God's words and teachings.

Furthermore, Clayton (2008) stated that pupils' consciousness about the good and the bad character and the characterization itself sends the message that power and evil can win out over innocence and 
mesmerized the children, touched them and comprehend the text to the outstanding level.

Alidou (1997) noted that effective teaching practices, active participation of students and better learning outcomes were observed in classes where a familiar language in which students and teachers are proficient was used Literacy is one of the main characteristics of academic learning. With regard to literacy, teacher training needs to improve in all types of schools so that students develop adequate literacy skills, which is often not the case even at the end of primary education.

\subsection{Relationship of Achievement and Literacy}

Mother Tongue-Based Teaching and Education for students highlights in more detail the correlations between students, language and marginality, and show that there are indeed positive links between the use of mother tongue in education and their participation and achievement in learning. While many challenges remain, the use of mother tongue in education has powerful pedagogical and social justifications and, thus, is a critical step in the right direction towards achieving Education for All.

More pupils enroll in school when they can learn in a language that is familiar to them. Pupils and their families may be less apprehensive about attending a school that uses their language and, by association, a familiar culture and set of values. Teachers in a bilingual program speak to students and their families in the L1, increasing family access to information about enrollment and schooling processes. School use of the home language increases parent participation and influence.

Improved communication allows parents to participate in school activities and decision-making, so that schools respond more to community needs and values. The resulting curriculum may better meet local needs, so that schooling becomes more relevant and productive for the pupils. Girls in bilingual classes stay long in school. Mother tongue-based schooling makes the home-school transition easier. Since pupils have less exposure to the second language, they feel more comfortable speaking and learning in the L1. They are more likely to enjoy school and perceive that schooling is relevant when they experience success, which will promote achievement, as well as the confidence to continue their school careers.

Students learn better and can demonstrate their learning in the Mother Tongue. Being able to talk to the teacher and other students in a familiar language allows girls to express the range of their thoughts and experiences, as well as demonstrate what they have learned.

In this way, too, teachers can make more realistic assessments of their capabilities and teach by building upon what they know, rather than filling their heads with meaningless memorized facts in a foreign language. It is too simplistic to claim that implementing mother tongue-based education will equalize opportunities for the students to excel have outstanding achievement in school.

Brock-Utne's and Alidou's comparative study of pupil performance in schools using familiar and unfamiliar languages of instruction reconfirms that pupils are more active and learn better in mother-tonguemedium schools. Kathy Au suggested that the literacy achievement gap can be closed by adhering to four, proven-effective keys to success, namely; recognizing that the solution must be multi-faceted, providing students with ample instruction in higher level thinking with text, building on the strengths that students bring from the home, and lastly, pulling schools together as places where teachers can collaborate to reach a shared vision of excellence in literacy achievement.

Bridging literacy and equity synthesizes the essential research and practice of social equity literacy teaching in one succinct, user-friendly volume. Extraordinary K-12 teachers show us what social equity literacy teaching looks like and how it advances children's achievement. Mother tongue-based bilingual education not only increases access to skills, but also raises the quality of basic education by facilitating classroom interaction and integration of prior knowledge and experiences with new learning.

Benson (2002), a leading scholar in the field of bi/multilingual education, claims that worldwide, children's L1has been established as the most efficient language for early literacy and content area instruction. Late transition to education in L2 is more effective than early transition. This perspective is echoed by Dutcher 
(1994), uttered the advantages of mother tongue-based education that individuals develop literacy skills and master content material most easily when they are taught in a familiar language and the best predictor of achievement in L2 is the level of development of language proficiency in L1.

As Anderson and Krathwohl (2001) cited that in order to develop literacy the cognitive process dimensions must be developed first because it is a good way to operationalize any pupils' progressions and that it provides a scheme for classifying educational goals, objectives, and standards.

\subsection{Synthesis}

The related literature and studies have something in common in which were found relevant to the present study that may furnish the researcher with insights that could be helpful in comparing, analyzing and interpreting the data gathered.

Aksan, Vardar and Tochon defined Mother Tongue as first language learned from mother and closed relatives at first that establishes a strong connection between as person and the society. Based on the international research conducted by the persons, Baker, Hornberger, Benson, Cummins, Thomas \& Collier agreed that at least some five years of instruction in the first language - but preferably throughout the education system - is required to provide a solid foundation for further studies.

Cummins, Kuntze, Golos, Enns and Svartholm were all quoted that a child who uses his own language is more proficient and like acquires literacy. Gest, Freeman, Domitrovich and Welsh emphasized that the pupils who are proficient in their own Mother Tongue achieved valuable and worthwhile activity and their achievements involves comprehending literary genres.

In addition to what they said; Kathy Au and Benson uttered that the literacy achievement gap can be closed and achieve success through the use of L1 or the language familiar to the students has been established as the most efficient language for early literacy and content area instruction.

Alidou and Rowe cited that attitudes towards attentiveness in the classroom and effective teaching practices, active participation of students and better learning outcomes were observed in classes where a familiar language in which students and teachers are proficient was used. As cited by John Walsh and Gold and Gibson there must be a number of steps in preparing to tell a literary genre and of course a set of pictures and printed for better consumption ad comprehension of the text. However, Paris and Cummins both agreed that if the pupils were exposed and practiced to those literary genres they proficient in it and are more likely to develop literacy.

As Benson and Dutcher identified and agreed that the children's overall educational attainment can be enhanced if they are taught in their mother tongue in early grades. Like what stated in series of studies noted as well as the statements quoted was found to have resemblance with this study, more specifically those which dealt on pupils' knowledge, comprehension, and appreciation of the literary genres presented before were written in their Mother Tongue. Furthermore, the achievements of pupils in terms of quarterly assessments, reading comprehension has also something to do with their proficiency in terms of their L1.

\section{Methods}

This section presents the method and statistical tools used to compute the data gathered from the sources of information. It also presents the research activities performed during the study such as: (a) research design, (b) identifying and choosing the respondents, (c) utilizing sampling size and sampling technique, (d) data gathering instrument, and (e) the statistical tools used that contributed a lot to the enrichment of the study. This provides the readers clear perspective on how the study was done and arrived at the given conclusions. 


\subsection{Research Design}

In this study, a quantitative correlational design was utilized. It is a formal, objective, systematic process for obtaining quantifiable information about the impact of Mother Tongue proficiency to the literary achievement of grade 3 pupils in the selected schools in the North District of Lipa City. In addition, the research describes the relationship of Mother Tongue proficiency to the literary achievement of the grade pupils.

The quantitative-descriptive method was used to gather data or describe the respondents. It described the relationship between literary comprehension through mother tongue and the achievement of Grade 3 pupils. Inferential method was employed to determine the differences between the literary comprehensions through Mother - Tongue to their achievement. Correlation method was also used to determine the relationship and significance of the agreement between the respondents and the literary comprehension through Mother Tongue and achievement of Grade 3 pupils in the North District.

\subsection{Sampling Technique}

The study was conducted in the Division of Lipa City, particularly in the North District. The schools under the district, unfortunately got the lowest score in the institutionalized result of LAPG for the School year 2014-2015. Twenty percent of the total population of each of the selected schools in the North District was chosen as respondents by means of purposive sampling technique. Black (2010) defines purposive sampling as a non-probability sampling method and it occurs when elements selected for the sample are chosen by the researcher. Researchers believed using purposive sampling a representative sample by using a sound judgment can be obtained which will also result to saving time and money.

\subsection{Respondents of the Study}

The researchers has taken the total enumeration of the respondents coming from the selected schools in the North District as reflected in Table 1. As shown in the table there is a total of 287 respondents who are all pupils in the North District.

Table 1. Respondents of the Study

\begin{tabular}{rlcc}
\hline School & & Number of Pupils & Percentage \\
\hline A. & SMKK Elementary School & 79 & $27.52 \%$ \\
B. & TMK Elementary School & 73 & $25.43 \%$ \\
C. & Abundio Torre & 28 & $9.75 \%$ \\
D. & Dagatan Elementary School & 27 & $9.40 \%$ \\
E. & Inosluban Elementary School & 80 & $27.87 \%$ \\
Grand Total & 287 & $100 \%$ \\
\hline
\end{tabular}

\subsection{Research Instruments}

The data gathering instruments used in this study is a teacher-made test. The teacher-made test questionnaire determined the literary comprehension through Mother Tongue on the literary genres like; poems, riddles, legend, fables, parables and short stories. These literary genres used Batangueno words (L1 of the respondents) while the following assessment tools/records (PHIL-IRI, Quarterly Assessment, and Report Cards) 
measure the Achievement of the Grade 3 pupils in the selected schools in the North District .

\subsection{Validation of the Questionnaire}

The researcher designed the questionnaire and presented the raft draft to the research adviser for comments and suggestions. The researcher made the necessary changes and adjustments to the questionnaires.

The instrument was validated by the experts on the literary genres who validate the questionnaires. These experts were given a copy of the statement of the problem and were interviewed by the researchers to find out whether the items therein were clear and appropriate for determining the literary comprehension through mother tongue and the achievement of Grade 3 pupils in the selected schools in the said district. The instrument validity was computed using the Content Validity Ratio (CVR) which obtained a value of 0.97 . The reliability test was obtained from the test-retest using 15 literary pieces presented to the grade 3 pupils in Pinagkawitan Elementary School. The test-retest was facilitated in two consecutive weeks. The pupils were given each copy of literary pieces and were asked to answer the questions after reading. The result was interpreted and evaluated using Cronbach's Alpha and obtained a value of 0.836. Table 2 presents the Table of Specification (TOS) that was used in the formulation of the test. The TOS highlighted the number of items in the different parts of the questionnaire.

Table 2. Table of Specifications used in Formulation of the Test

\begin{tabular}{lccc}
\hline Content & Item Placement & Number of Items & Percentage \\
\hline Poems & $1-10$ & 10 & $16.66 \%$ \\
Short Stories & $11-20$ & 10 & $16.66 \%$ \\
Riddles & $21-30$ & 10 & $16.66 \%$ \\
Parables & $31-40$ & 10 & $16.66 \%$ \\
Fables & $40-50$ & 10 & $16.66 \%$ \\
Legends & $51-60$ & 10 & $16.66 \%$ \\
Total & & 60 & $100 \%$ \\
\hline
\end{tabular}

\subsection{Statistical Tools}

The statistical procedure used in the analysis of the data were: Pearson r Correlation Coefficient, TTest, Standard Deviation, frequency count, percentage, and weighted mean to determine the extent to which the respondents rated or evaluated the items according to their perceptions. Pearson $r$ was used to find out if there is any significant relationship between the challenges encountered by Science teachers and pupil performance. $\mathrm{T}$ - test was used to understand how to calculate the significance of observed differences between the means of two samples when there is null hypothesis. Weighted Mean was used to determine the typicality of responses chosen from options in the given scale on the respondent's responses to the questionnaire items provided in the research instrument. Standard deviation was used to measure the dispersion of a given data set. It indicated how close to the average the data when clustered. It was used to measure the confidence in statistical data. 


\section{Presentation, Analysis, and Interpretation of Data}

This section presents the results, analysis and interpretation of data gathered. The said data were presented in tabular form in accordance with the specific questions posited on the statement of the problem.

\subsection{Level of Comprehension of Grade 3 Pupils in Literary Genres}

To determine the level of literary comprehension through mother tongue of the Grade 3 pupils in the literary genres, each table shows the scores with interpretation, the frequency count, the percentage, its rank, the mean score and the standard deviation. The literary genres given and used in this study were written in the "Batangueño dialect" which is the respondents' L1 or Mother Tongue. Table 3.1 shows the level of comprehension of grade 3 pupils in terms of poems incorporating Batangueño dialect.

Table 3.1 Level of Comprehension of Grade 3 Pupils in Literary Genres in Terms of Poems

\begin{tabular}{llccc}
\hline Scores & F & P & Rank \\
\hline $9-10$ (Outstanding) & 148 & 51.57 & 1 \\
$7-8 \quad$ (Very Satisfactory) & 114 & 39.72 & 2 \\
$5-6 \quad$ (Satisfactory) & 22 & 7.67 & 3 \\
$3-4$ & (Fairly Satisfactory) & 1 & 0.35 & 5 \\
$0-2$ & (Did Not Meet Expectation) & 2 & 0.70 & 4 \\
& $\mathbf{2 8 7}$ & $\mathbf{1 0 0}$ \\
Total & \multicolumn{3}{c}{$\mathbf{1 0}$} \\
Number of Items & \multicolumn{2}{c}{$\mathbf{1 0}$ (Outstanding) } \\
Highest Score & \multicolumn{2}{c}{$\mathbf{2}$ (Did Not Meet } \\
Lowest Score & \multicolumn{3}{c}{ Expectation) } \\
& $\mathbf{2 . 4 1 ( V e r y ~ S a t i s f a c t o r y ) ~}$ \\
Mean Score & \multicolumn{2}{c}{$\mathbf{1 . 4 2}$} \\
Standard Deviation & \multicolumn{3}{c}{} \\
\hline
\end{tabular}

As can be seen in Table 3.1, the outstanding scores of $9-10$ made the highest frequency count of 148 or $51.57 \%$ at rank 1 for the student's level of comprehension in poems. These were followed by the very satisfactory scores of $7-8$, satisfactory scores of 5-6 and did not meet expectation score of $0-2$ with frequency counts of 114, 22 and two or $39.72 \%, 7.67$ and 0.70 at ranks 2, 3 and 4, respectively. The fairly satisfactory score of 3-4 got the least frequency count of one or $0.35 \%$ at rank 5 . This finding proves that if the students were given genres written in a Mother - tongue-based program there will be a very satisfactory result.

Out of 10 items, the highest score was 10 (outstanding), the lowest was two (did not meet expectation), and the mean score was 8.41 (very satisfactory). If these scores of the students in a 10 -item test is to be interpreted statistically using the passing score of 5 as the norm, the mean score of the students fall way above the average level ranges from 3.58 to 6.42 (one standard deviation plus and minus the assumed mean). This is an indication that Grade III pupils attain above the desirable level of comprehension on literary genres in terms of poems. It implies further that Grade III pupils are able to develop full and functional understanding of literary genres in terms of poems.

The pupils were able to comprehend the poems in a very satisfactory level because they were exposed to it. Poem is one of the most frequent use springboards in the classroom. The teachers strove a lot of effort to extend and expand both their knowledge and appreciation of poetry. They knew what should be given emphasis 
in analysing and comprehending a poem type of literary genre. Aside from these, the teachers' choice of poems was highly commendable because they chose poems with plenty of rhyming words that capture the pupils' interest. These expressed their past experiences, thoughts and strong feelings about something.

Jump-up (Puffin, 1990) declared that one of the great things about teaching poetry in the primary grades is that they already come to you with openness for the genre. They will also have had some exposure to the genre due to its frequent use in the primary grade classrooms. We want them to understand that good poemspowerful words and images- amuse and motivate us in, any ways. This case is also true and proves the famous words of Nelson Mandela, "That if you speak to a man in a language he understands, you speak to his brain. But if you speak to him in his own language, you speak to his heart."

Table 3.2 describes the comprehension level of grade 3 pupils in terms of short stories written in their mother tongue.

Table 3.2. Level of Comprehension of Grade 3 Pupils in Literary Genres in Terms of Short Stories

\begin{tabular}{llccc}
\hline Scores & F & P & Rank \\
\hline $9-10$ (Outstanding) & 133 & 46.34 & 1 \\
$7-8$ & (Very Satisfactory) & 95 & 33.10 & 2 \\
$5-6$ & (Satisfactory) & 40 & 13.94 & 3 \\
$3-4$ & (Fairly Satisfactory) & 18 & 6.27 & 4 \\
$0-2$ & (Did Not Meet Expectation) & 1 & 0.35 & 5 \\
Total & $\mathbf{2 8 7}$ & $\mathbf{1 0 0}$ \\
Number of Items & \multicolumn{2}{c}{$\mathbf{1 0}$ (Outstanding) } \\
Highest Score & \multicolumn{2}{c}{$\mathbf{2}$ (Did Not Meet } \\
Lowest Score & \multicolumn{3}{c}{ Expectation) } \\
& \multicolumn{2}{c}{$\mathbf{7 . 8 5}$ (Very Satisfactory) } \\
Mean Score & \multicolumn{3}{c}{$\mathbf{1 . 7 9}$} \\
Standard Deviation
\end{tabular}

As can be seen in Table 3.2, 133 out of 287 total-student-respondents or $46.34 \%$ at rank 1 got outstanding scores of $9-10$ for their level of comprehension in short stories. Came next were the very satisfactory scores of $7-8$, satisfactory scores of $5-6$ and fairly satisfactory scores of $3-4$ with frequency counts of 95, 40 and 18 or $33.10 \%, 13.94$ and 6.27 at ranks 2, 3 and 4, respectively. Meanwhile, the scores of 0 -2 (did not meet expectation) gained the least frequency count of one or $0.35 \%$ at rank 5 . The pupils' gained a very satisfactory level of comprehension in terms of short stories.

The highest score was 10 (outstanding), the lowest was two (did not meet expectation) and the mean score was 7.85 (very satisfactory) out of 10 items.

The results indicate that the pupils' level of comprehension in the literary genres in terms of short stories fall higher than the satisfactory level of comprehension if the norm to be used is the passing score of 5 out of 10 item examinations. Using the assumed mean, the expected range of the satisfactory level is 3.21 to 6.79 (one standard deviation plus and minus the assumed mean). This indicates that the 7.85 mean results fall higher than the expected satisfactory level of comprehension in literary genres using short stories as a measure.

The finding shows that Grade III pupils are competent, and the attainment of the comprehension level is significantly higher than the expected level of comprehension. Majority of the students manifest the outstanding level of comprehension in literary genres in terms of short stories because the teachers presented the short story in a step-by-step procedure. This started with unlocking of vocabulary words in order for them to fully understand the text. The teachers provided the pictures that caught their interest for the content with 
pleasure.

Aside from these the teachers also used the reading aloud of the short stories that has positive effects on the development of reading comprehension and vocabulary. It helps building their creative imaginations and builds listening skills.

These findings were in harmony to the claims of Rog (2001) who states that reading the stories mean to develop children's concepts about print, story structure, and other elements of text and provides the child with a wealth of information about the processes and functions of written language.

On the other hand, the teacher must use strategy in order for the pupils to well comprehend the short stories like reading aloud. Just like what Needlman (2004) asserted that there are many reasons to read aloud to students. These include: (1) Reading together is fun; (2) Reading aloud keeps interest high; (3) reading aloud builds listening skills; (4) reading aloud builds vocabulary and lastly (5) stories are the building blocks of imagination.

Moreover, the importance of reading aloud to children has been demonstrated in the results of over 75 years of educational research, (Wood, 1994). Furthermore, Gold and Gibson (2001) emphasize that reading aloud is the foundation of literacy development and that in demonstrates the relationship between the printed word and meaning and invites the listener into conversation with the author that result to a very satisfactory level of comprehension.

Table 3.3 shows the literary level of comprehension of grade 3 pupils in terms of riddles written in their vernacular language.

Table 3.3 Level of Comprehension of Grade 3 Pupils in Literary Genres In Terms of Riddles

\begin{tabular}{llcc}
\hline Scores & F & P & Rank \\
\hline $9-10$ (Outstanding) & 105 & 36.59 & 2 \\
$7-8 \quad$ (Very Satisfactory) & 114 & 39.72 & 1 \\
$5-6 \quad$ (Satisfactory) & 48 & 16.72 & 3 \\
$3-4 \quad$ (Fairly Satisfactory) & 15 & 5.23 & 4 \\
$0-2 \quad$ (Did Not Meet Expectation) & 5 & 1.74 & 5 \\
Total & $\mathbf{2 8 7}$ & $\mathbf{1 0 0}$ \\
Number of Items & \multicolumn{3}{c}{$\mathbf{1 0}$ (Outstanding) } \\
Highest Score & \multicolumn{2}{c}{ 2 (Did Not Meet } \\
Lowest Score & \multicolumn{2}{c}{ Expectation) } \\
Mean Score & $\mathbf{7 . 5 4}$ (Very Satisfactory) \\
Standard Deviation & \multicolumn{3}{c}{$\mathbf{1 . 8 2}$} \\
\hline
\end{tabular}

As shown in Table 3.3, 114 out of 287 total-student-respondents or $39.72 \%$ at rank 1 got very satisfactory scores of $7-8$ for their level of comprehension in riddles. These were followed by the outstanding scores of $9-10$, satisfactory scores of $5-6$ and fairly satisfactory scores of $3-4$ with frequency counts of 105 , 48 and 15 or $36.59 \%, 16.72$ and $5.23 \%$ at ranks 2,3 and 4 , respectively. On the other hand, the scores of $0-2$ (did not meet expectation) gained the least frequency count of five or $1.74 \%$ at rank 5 .

Furthermore, this signifies that the Grade 3 pupils reap very satisfactory level of comprehension on literary genres in terms of riddles. Out of 10 items, the highest score was 10 (outstanding), the lowest was two (did not meet expectation), and the mean score was 7.54 (very satisfactory) out of 10 items. The results show that the pupils' level of comprehension in the literary genres in terms of riddles fall higher than the satisfactory level of comprehension if the norm to be used is the passing score of 5 out of $10-$ item examinations. Using the assumed mean, the expected range of the satisfactory level is 3.18 to 6.82 (one standard deviation plus and 
minus the assumed mean). This suggests that that the 7.54 mean results fall higher that the expected satisfactory level of comprehension in literary genres using riddles as a measure.

The pupils were able to reach the very satisfactory level of comprehension because their teachers presented the riddles in their daily classroom discussions as games that elicit pupils' attentiveness, critical and creative thinking skills. It could be implied further that they are very satisfactory when it comes to riddles because they are using these in their daily living, in their jokes, pick-up lines and conversations with their friends, relatives and family and so they are proficient in it. This is supported by the findings of the study conducted by Cummins (1991) that a well-developed first language used in the daily activities of the child such as those use and practice while chatting with classmates, friends and subordinates is the spring board of the acquisition of all types of learning and make them proficient when it comes to comprehension and are more likely to develop literacy. In additions, Paris (2003) has demonstrated that children develop riddles schema through repeated exposure to riddles. That the riddles employ a guessing game structure leads to an intention to achieve a goal that proposed the ability to use, identify, organize and understand information from text in order to arrive to correct answer.

Table 3.4 presents the pupils' level of comprehension in terms of parables.

Table 3.4 Level of Comprehension of Grade 3 Pupils in Literary Genres in Terms of Parables

\begin{tabular}{|c|c|c|c|}
\hline Scores & $\mathbf{F}$ & $\mathbf{P}$ & Rank \\
\hline 9-10 (Outstanding) & 159 & 55.40 & 1 \\
\hline $7-8$ (Very Satisfactory) & 86 & 29.97 & 2 \\
\hline $5-6 \quad$ (Satisfactory) & 30 & 10.45 & 3 \\
\hline $3-4$ (Fairly Satisfactory) & 11 & 3.83 & 4 \\
\hline $0-2$ (Did Not Meet Expectation) & 1 & 0.35 & 5 \\
\hline Total & 287 & 100 & \\
\hline Number of Items & \multirow{2}{*}{\multicolumn{3}{|c|}{$\begin{array}{c}10 \\
10 \text { (Outstanding) }\end{array}$}} \\
\hline Highest Score & & & \\
\hline Lowest Score & \multicolumn{3}{|c|}{$\begin{array}{l}0 \text { (Did Not Meet } \\
\text { Expectation) }\end{array}$} \\
\hline Mean Score & \multirow{2}{*}{\multicolumn{3}{|c|}{$\begin{array}{c}8.30 \text { (Very Satisfactory) } \\
1.79\end{array}$}} \\
\hline Standard Deviation & & & \\
\hline
\end{tabular}

Data in Table 3.4 revealed that out of 287 total-respondents, 159 or $33.40 \%$ at rank 1 got outstanding scores of $9-10$ for their level of comprehension in parables. Next were on very satisfactory scores of $7-8$, satisfactory scores of $5-6$ and fairly satisfactory scores of $3-4$ with frequency counts of 86,30 and 11 or $29.97 \%, 10.45 \%$ and $3.83 \%$ at ranks 2,3 and 4 , respectively. On the contrary, the scores of $0-2$ (did not meet expectation) gained the least frequency count of one or $0.35 \%$ at rank 5 . The findings of the study tell that grade III pupils have a very satisfactory level comprehension in terms of parables.

It could be implied that the grade 3 pupils acquire a very satisfactory level of comprehension in terms of parables because the story is probably neither related nor similar to the stories told by them by their teachers and parents. That since birth they were told stories about Jesus and stories with good moral lessons to derive from. The pupils were very acquainted with what to do in times of trouble so that they grow as good citizen of the country. In conformity with the study conducted by Tomasulo and Pawelski (2012); parables are didactic stories that were initially composed and orally transmitted in order to teach a pertinent life lesson and to guide children on how to live a morally upstanding life through God's words and teachings. The highest score was 10 (outstanding), the lowest was zero (did not meet expectation), and the mean score was 8.30 (very satisfactory) 
out of 10 items. The findings of the study show how the pupils in grade III are fond of reading the story coming from the Bible and how are they able to comprehend it the most is just because it is written to the language familiar to them.

Table 3.5 shows the level of comprehension of grade 3 pupils in terms of fables incorporating mother tongue.

Table 3.5 Level of Comprehension of Grade 3 Pupils in Literary Genres in Terms of Fables

\begin{tabular}{lccc}
\hline Scores & F & P & Rank \\
\hline $9-10$ (Outstanding) & 32 & 11.15 & 4 \\
$7-8$ (Very Satisfactory) & 96 & 33.45 & 1 \\
$5-6 \quad$ (Satisfactory) & 86 & 29.97 & 2 \\
$3-4 \quad$ (Fairly Satisfactory) & 58 & 20.21 & 3 \\
$0-2$ (Did Not Meet Expectation) & 15 & 5.23 & 5 \\
Total & $\mathbf{2 8 7}$ & $\mathbf{1 0 0}$ & $\mathbf{1 0}$ \\
Number of Items & \multicolumn{3}{c}{$\mathbf{1 0}$ (Outstanding) } \\
Highest Score & \multicolumn{2}{c}{ (Did Not Meet } \\
Lowest Score & \multicolumn{2}{c}{ Expectation) } \\
Mean Score & \multicolumn{3}{c}{$\mathbf{2 . 0 8}$} \\
Standard Deviation & \multicolumn{3}{c}{} \\
\hline
\end{tabular}

As reflected in Table 3.5, 96 out of 287 total-student-respondents or $33.45 \%$ at rank 1 got very satisfactory scores of $7-8$ for their level of comprehension in fables. These were followed by the satisfactory scores of 5-6, fairly satisfactory scores of $3-4$ and outstanding scores of $9-10$ with frequency counts of 86 , 58 and 32 or $29.97 \%, 20.21 \%$ and $11.15 \%$ at ranks 2,3 and 4 , respectively. Contrariwise, the scores of $0-2$ (did not meet expectation) obtained the least frequency count of 15 or 5.23\% at rank 5. The pupils' level of comprehension is satisfactory in terms of fables.

Out of 10 items, the highest score was 10 (outstanding), the lowest was one (did not meet expectation), and the mean score was 5.99 (satisfactory) out of 10 items. If these scores of the students in a 10-item test is to be interpreted statistically using the passing score of 5 as the norm, the mean score of the pupils fall below the average level or fairly satisfactory level. This is because the satisfactory level ranges from 2.92 to 7.08 (one standard deviation plus and minus the assumed mean). It implies that children were well versed with stories having animals as characters. They found it fun and interesting when the animals talk and behave as if they really do in real life. They enjoyed a story a lot having animals as protagonist and antagonist and whose response to an initial event leads to an intention and whose subsequent actions, conflicts and resolutions result in a clearly stated outcome. These actions and scenes in the story are needed for comprehending not only the sequence of events but also why the events took place and what judgments might be made about them.

On the other hand, the pupils achieved satisfactory level of understanding because fables are a particular kind of story with their own structure and a lesson to be learned. They know that a good deed will be rewarded, and a bad action will be given punishment. Pelletier and Astington (2004) asserted that fables are cautionary tales in which (typically) an animal symbolizing a human character flaw (greed, arrogance, stupidity, timidity, naïve, and carelessness) which is needed to be punished and the good character is rewarded. However, Clayton (2008) stated that the pupils' consciousness about the good and the bad character and the characterization itself sends the message 
that power and evil can win out over innocence and good will unless thoughtful action is taken mesmerized the children that make them really touched and comprehend the narrative text to the outstanding level.

Table 3.6 shows the pupils' level of comprehension in terms of legends using mother tongue as a medium.

Table 3.6 Level of Comprehension of Grade 3 Pupils in Literary Genres in Terms of Legends

\begin{tabular}{llccc}
\hline Scores & F & P & Rank \\
\hline $9-10$ (Outstanding) & 96 & 33.45 & 1 \\
$7-8 \quad$ (Very Satisfactory) & 86 & 29.97 & 2 \\
$5-6 \quad$ (Satisfactory) & 57 & 19.86 & 3 \\
$3-4 \quad$ (Fairly Satisfactory) & 40 & 13.94 & 4 \\
$0-2 \quad$ (Did Not Meet Expectation) & 8 & 2.79 & 5 \\
Total & $\mathbf{2 8 7}$ & $\mathbf{1 0 0}$ \\
Number of Items & \multicolumn{2}{c}{$\mathbf{1 0}$ (Outstanding) } \\
Highest Score & \multicolumn{3}{c}{$\mathbf{2}$ (Did Not Meet } \\
Lowest Score & \multicolumn{3}{c}{ Expectation) } \\
& $\mathbf{2 . 1 3}$ (Very Satisfactory) \\
Mean Score & \multicolumn{3}{c}{$\mathbf{2 . 3 0}$} \\
Standard Deviation & \multicolumn{3}{c}{} \\
\hline
\end{tabular}

As presented in Table 3.6, 96 out of 287 total-student-respondents or $33.45 \%$ at rank 1 got outstanding scores of $9-10$ for their level of comprehension in legends. Next were on very satisfactory scores of $7-8$, satisfactory scores of 5-6 and fairly satisfactory scores of $3-4$ with frequency counts of 86,57 and 40 or $29.97 \%, 19.86 \%$ and $13.94 \%$ at ranks 2, 3 and 4, respectively. Meanwhile, the scores of $0-2$ (did not meet expectation) obtained the least frequency count of eight or $2.79 \%$ at rank 5 . The level of comprehension of pupils in terms of legend is very satisfactory. The highest score was 10 (outstanding), the lowest was two (did not meet expectation), and the mean score was 7.13 (very satisfactory) out of 10 items. If these scores of the Grade III pupils in a 10-item test is to be interpreted statistically using the passing score of 5 as the norm, the mean score of the students fall way. This is because the satisfactory level ranges from 0.57 to 7.3 (one standard deviation plus and minus the assumed mean). This indicates that the 7.13 mean falls higher than the expected satisfactory level of comprehension in literary genres using fables as a measure.

This further implies that Grade 3 pupils are competent, and the attainment of the comprehension level is significantly higher than the expected level of comprehension. The pupils comprehend the legend in a very satisfactory level because they are curious on how things came into existence. The teacher might use strategy in telling the legend. The teachers might be able to prepare all the audio-visual materials and so they'll able to arouse the interest and curiosity of the pupils. Furthermore, the transitions of these stories remind and make them aware and remember our culture. John Walsh (2003) outlines a number of steps in preparing to tell a story, particularly legend stories. He reminds us that not only has our culture changed in the way we receive information, but also how we remember it. The analytical listener and the teacher respond to the order of the presentation, but other kinds of listeners respond to pictures and illustrations. They understand the story better if they were presented in visual representations and so the learning happened.

As depicted in this table despite of the numerous numbers of grade 3 pupils who achieved commendable achievement in terms of legends there's still few who were not able to meet the expectation.

Comparing all the obtained means, it was found out that poem was the easiest while fable was the most difficult. In terms of variability, scores in poem were the most compressed while scores in legends were the 
most dispersed as evidenced by the obtained standard deviations of 1.42 and 2.30 , respectively. Since the respondents of the study were all in primary grade and they all enjoyed themselves reading poems with rhyming words and the poem was written in a language well-known to them the respondents find it the easiest.

The Grade 3 pupils were animal lovers and since the fable talks the animals as their protagonist and antagonist, the researcher found it unbelievable that they found it the most difficult among the literary genres given to them. The first stories that have been told to them as kids were probably poems. Rhymes play an important role for their child development.

Fox (2001) uttered that experts in literacy and child development have discovered that if children know eight nursery rhymes by heart by the time, they're four years old, they're usually among the best readers by their eight. In addition to what Fox said, Hadaway, Vardell and Young (2001) all agreed that rhymes make I easier for kids to learn new words. Learning new words appears effortless, because the rhythmical structure of the stanzas creates a familiar context for unfamiliar words and poetry provides a relaxed and pleasant way for students to practice language skills. Furthermore, the grade 3 pupils found the fable as the most difficult one this is because the kids now are a lot smarter than we ever give them credit Keleman (2014) says. They can handle a surprising degree of complexity when you frame things in a way that taps into the natural human drive for a good, cohesive explanation. And because what is real from a fancy one, they got confused about which and what to answer that find it hard to answer the questions regarding the fables stories even they were written in the common language.

\subsection{Achievement of the Grade 3 Pupils in the Different Assessment Tools Integrating Mother Tongue as Medium of Instruction}

To determine the achievement of the Grade 3 pupils in the different assessment tools, namely; PHILIRI, Quarterly assessment, and Report cards integrating mother tongue as a medium of instruction, tables 2.1 up to 2.3 presented the scores and its interpretation, mean score and standard deviation.

Table 4.1 shows the achievement of grade 3 pupils in PHIL-IRI as an assessment tool incorporating mother tongue as a medium of instruction.

Table 4.1 Achievement of the Grade 3 Pupils in PHIL-IRI as Assessment Tool Integrating Mother Tongue as Medium of Instruction

\begin{tabular}{llcc}
\hline Scores & F & P & Rank \\
\hline $12-14$ (Outstanding) & 76 & 26.48 & 2 \\
$9-11$ (Very Satisfactory) & 134 & 46.69 & 1 \\
$6-8 \quad$ (Satisfactory) & 64 & 22.30 & 3 \\
$3-5 \quad$ (Fairly Satisfactory) & 13 & 4.53 & 4 \\
$0-2 \quad$ (Did Not Meet Expectation) & 0 & 0 & 5 \\
Total & $\mathbf{2 8 7}$ & $\mathbf{1 0 0}$ \\
Number of Items & \multicolumn{2}{c}{$\mathbf{1 4}$ (Outstanding) } \\
Highest Score & $\mathbf{4}$ (Fairly Satisfactory) \\
Lowest Score & $\mathbf{9 . 9 1}$ (Very Satisfactory) \\
Mean Score & \multicolumn{3}{c}{$\mathbf{2 . 4 8}$} \\
Standard Deviation
\end{tabular}

As can be gleaned in the table, the highest score obtained by the pupils is 14 out of 14 -item test. The majority of the students score is in the very satisfactory level which corresponds to $46.69 \%$. The mean score of 
the pupils in this examination is 9.91 with the standard deviation of 2.48 . if the assumed mean of 7 is used being the norm for this test, the range of 4.52 to 9.48 which is one plus and minus the standard deviation of the assumed mean denotes that the student's level of achievement is higher than the expected satisfactory level. The grade 3 pupils were able to read well and obtained the very satisfactory level.

The findings imply that the grade III pupils' comprehension level and fluency within the context of oral and silent assessment in the PHIL-IRI were very satisfactory because the reading piece given to them depends and in accordance with their grade level. The teacher probably applied a step-by-step procedure in making the students learn how to read. The diligent teachers use the specific instruction in the major parts of teaching reading first is the phonemes, vocabulary and then comprehension by asking HOTS. They planned well what to read, where to focus.

Table 4.2 describes the pupils' achievement in quarterly assessment as a tool integrating mother tongue as a medium of instruction.

Table 4.2 Achievement of the Grade 3 Pupils in Quarterly Assessment as Tool Integrating Mother Tongue as Medium of Instruction

\begin{tabular}{llccc}
\hline Scores & & F & P & Rank \\
\hline $32-40$ & (Outstanding) & 65 & 22.65 & 3 \\
$24-31$ & (Very Satisfactory) & 151 & 52.61 & 1 \\
$16-23$ & (Satisfactory) & 67 & 23.34 & 2 \\
$8-15$ & (Fairly Satisfactory) & 4 & 1.39 & 4 \\
$0-7$ & (Did Not Meet Expectation) & 0 & 0 & 5 \\
Total & $\mathbf{2 8 7}$ & $\mathbf{1 0 0}$ \\
Number of Items & \multicolumn{3}{c}{$\mathbf{4 0}$ (Outstanding) } \\
Highest Score & $\mathbf{4 3}$ (Fairly Satisfactory) \\
Lowest Score & $\mathbf{2 7 . 3 7}$ (Very Satisfactory) \\
Mean Score & \multicolumn{3}{c}{$\mathbf{5 . 1 3}$} \\
Standard Deviation
\end{tabular}

As can be gleaned in Table 4.2, the very satisfactory scores of $24-31$ obtained the highest frequency count of 151 or $52.61 \%$ at rank 1 shows that the achievement of Came next were on the satisfactory scores of $16-23$ and outstanding scores of $32-41$ with frequency counts of 67 and 65 or $23.34 \%$ and $22.65 \%$ at ranks 2 and 3, respectively. The fairly satisfactory scores of $8-15$ made the least frequency count of four or $1.39 \%$ at rank 4. Out of 40 items, the highest was 40 (outstanding), the lowest was 13 (fairly satisfactory) and the mean score was 27.37 (very satisfactory).

Therefore Grade 3 pupils having mother tongue as a medium of instruction have a very satisfactory level of achievement. The findings imply that the teachers were all prepared for their everyday teachings. The teaching materials were ready to use that made the pupils learn what they supposed to learn. Furthermore, the pupils are involved not just by merely looking or listening to the teacher, but as well in the process of learning. Today's curriculum is learner-centered wherein the teachers are only the facilitator of the teaching learning process.

The grade 3 pupils achieved the very satisfactory level because of the teachers' hard work in providing instructional and appropriate teaching materials because the pupils of today's generation are more audio-visual learners. This will help them for better integration and inculcation of the lessons on the part of the pupils. The response is paralleled to the statement of Hall (2010) as cited by Dekker, et al; (2008), that is, no teacher can teach effectively without appropriate materials that are based on two components; established government curriculum goals and pupils' prior knowledge, culture and system. 
This is congruent with Grant (1978) as cited by Sunday \& Joshua (2010) statement that says that "Teaching and learning cannot be effective without adequate and relevant use of instructional materials. In addition to Malone (2007) definitely agreed on this and stated that literacy can only be maintained if there is an adequate supply of reading materials. Looking at it, it is now well established that children who receive assessment in their mother tongue language in early grades have better learning outcomes overall and, in particular, significantly better literacy levels.

Table 4.3 shows the achievement of the grade 3 pupils in the report cards as an assessment tool integrating mother tongue as a medium of instruction.

Table 4.3 Achievement of the Grade 3 Pupils in Report Card Grades as Assessment Tool Integrating Mother Tongue as Medium of Instruction

\begin{tabular}{|c|c|c|c|}
\hline Scores & $\mathbf{F}$ & $\mathbf{P}$ & Rank \\
\hline $90-100$ (Outstanding) & 24 & 8.36 & 4 \\
\hline $85-89$ (Very Satisfactory) & 75 & 26.13 & 2 \\
\hline $80-84$ (Satisfactory) & 125 & 43.55 & 1 \\
\hline $75-79$ (Fairly Satisfactory) & 63 & 21.95 & 3 \\
\hline Below 75 (Did Not Meet Expectation) & 0 & 0 & 5 \\
\hline Total & 287 & 100 & \\
\hline Highest Grade & \multicolumn{3}{|c|}{98 (Outstanding) } \\
\hline Lowest Grade & \multicolumn{3}{|c|}{75 (Fairly Satisfactory) } \\
\hline Mean Score & \multicolumn{3}{|c|}{82.98 (Satisfactory) } \\
\hline Standard Deviation & \multicolumn{3}{|c|}{4.47} \\
\hline
\end{tabular}

As can be seen in Table 4.3, the satisfactory grades of $80-84$ made the highest frequency count of 125 or $43.55 \%$ at rank 1 . These were followed by the very satisfactory grades of $85-89$ and fairly satisfactory grades of $75-79$ with frequency counts of 75 and 63 or $26.13 \%$ and $21.95 \%$ at ranks 2 and 3, respectively. The least frequency count of 24 or $8.36 \%$ at rank 4 was gained by the outstanding grades of $90-100$. (The highest grade was 98 (outstanding), the lowest was 75 (fairly satisfactory) and the mean grade was 82.98 (satisfactory). The finding itself shows that majority of the grade III pupils have a satisfactory grade as seen on their report cards.

It simply implied that the pupils in grade III have low performance in the performance task component of the summative assessment. The performance task is about $50 \%$ of pupils' grade, which means that even she perfected the Quarterly assessment nor in the written work component, but they don't cooperate with the group activity or any performance-based task required them to perform, average grades came as an output. Classroom assessment is an integral part of curriculum implementation. It allows the teachers to track and measure learners' progress and to adjust instruction accordingly. Classroom assessment informs the learners, as well as their parents and guardians of their progress and it is reflected on their report cards.

Assessment in the classroom before they became grades in cards comprises content standards, performance standards, and learning competencies that are outlined in the curriculum. Since the K-12 curriculum focuses and put emphasis on a performance-based tasks, the students who show what they know and are able to do in diverse ways. They may create or innovate products or do performance-based tasks other than passing the written exams gain higher grades in the card which follows and having the transmuted grades (DepEd Order no.8, series of 2015). Nevertheless, the pupils who passed the classroom assessment in their quizzes, monthly test, or any written work, but unfortunately failed to work cooperatively in group work activity and whose skills weren't expressed through creation, innovation, and adding value to products/performance 
during independent work or in collaboration with others achieved satisfactory or worst fairly satisfactory grades because they didn't show/ reflect progressions on concept development prescribed by the rubrics as bases in the grading of the presented performance task. This supports the concept of Anderson and Krathwohl (2001) that the Cognitive process dimensions may be a good way to operationalize any pupils' progressions. It provides a scheme for classifying educational goals, objectives, and standards.

\subsection{Significant Relationship Between the Level of Comprehension and Literary Achievement of Grade 3 Pupils.}

Table 5 presents the significant relationship between level of comprehension and literacy achievement of Grade 3 pupils. The achievement levels of Grade 3 pupils were used to relate to the findings of the different assessment tools: PHIL-IRI, Quarterly assessment and report cards. The second column provides the basis to determine the statistical significance of the relationship between the variables compared in the table. Since there is a consistent number of 287 respondents in this study, the computed value of $\boldsymbol{r}$ for each variable were compared. To test the significance of the relationship, the $\mathrm{P}$ value for each variable is indicated in the decision column as the basis for the decision whether there is a significant or no significant relationship at 0.05 level of significance. The last column provides the decision whether to reject or accept the null hypothesis or gives significant relationship between level of comprehension and literary achievement of grade III pupils.

The significant relationship existing between the level of comprehension in the presented literary genres, namely: poems, short stories, riddles, parables, fables, and legends and the pupils' achievement in the following assessment tools in PHIL-IRI, Quarterly assessment, and report cards integrating mother tongue as a medium of instruction.

Table 5. Significant Relationship Between the Level of Comprehension and Literary Achievement of Grade 3 Pupils

\begin{tabular}{llll}
\hline Variables & r & p-value & Decision \\
\hline Poem's Achievement versus: & & & \\
$\quad$ PHIL - IRI & 0.56 & $0.000^{* *}$ & Reject Ho \\
$\quad$ Quarterly Assessment & 0.15 & $0.000^{* *}$ & $\begin{array}{l}\text { Reject Ho } \\
\text { Reject Ho }\end{array}$ \\
$\quad$ Report Card & 0.35 & $0.000^{* *}$ & \\
Short Stories Achievement versus: & & & \\
$\quad$ PHIL - IRI & 0.55 & $0.000^{* *}$ & Reject Ho \\
$\quad$ Quarterly Assessment & 0.09 & 0.064 & Accept Ho \\
$\quad$ Report Card & 0.32 & $0.000^{* *}$ & Reject Ho \\
Riddles Achievement versus: & & & \\
$\quad$ PHIL - IRI & 0.55 & $0.000^{* *}$ & Reject Ho \\
$\quad$ Quarterly Assessment & 0.07 & 0.117 & Accept Ho \\
$\quad$ Report Card & 0.24 & $0.000^{* *}$ & Reject Ho \\
Parables Achievement versus: & & & \\
$\quad$ PHIL - IRI & 0.57 & $0.000^{* *}$ & Reject Ho \\
$\quad$ Quarterly Assessment & 0.14 & $0.000^{* *}$ & Reject Ho \\
$\quad$ Report Card & 0.40 & $0.000^{* *}$ & Reject Ho \\
Fables Achievement versus: & & & \\
$\quad$ PHIL - IRI & 0.57 & $0.000^{* *}$ & Reject Ho \\
$\quad$ Quarterly Assessment & 0.09 & 0.064 & Accept Ho \\
$\quad$ Report Card & 0.37 & $0.000^{* *}$ & Reject Ho \\
\hline
\end{tabular}




\begin{tabular}{llll}
\hline Legends Achievement versus: & & & \\
PHIL - IRI & 0.59 & $0.000^{* *}$ & Reject Ho \\
Quarterly Assessment & 0.09 & 0.064 & Accept Ho \\
Report Card & 0.36 & $0.000^{* *}$ & Reject Ho \\
\hline ** Significant at 0.01 & $*$ Significant at 0.05 &
\end{tabular}

As can be seen in the table, the probability values for poem's achievement versus PHIL-IRI, quarterly assessment and report card; parables achievement versus PHIL-IRI, quarterly assessment and report card; riddles achievement versus PHIL-IRI and report card; fables achievement versus PHIL-IRI and report card; and legends achievement versus PHIL-IRI and report card were less than the probability values at 0.01 , thus rejecting the null hypothesis.

The findings concluded that poem's achievement and PHIL-IRI, quarterly assessment and report card; parables achievement and PHIL-IRI, quarterly assessment and report card; riddles achievement and PHIL-IRI and report card; fables achievement versus PHIL-IRI and report card; and legends achievement and PHIL-IRI and report card have high significant relationships. This means that there is a significant relationship between the level of the student's comprehension and the level of literary achievement.

Significant in the findings of this study is that quarterly assessment which generally has no significant relationship in the level of achievement and comprehension when mother tongue is used using the most of the variables. The only significant relationship established in the findings in quarterly assessment and level of comprehension is when parable is used in the measure. All other tools of measurement used to determine the comprehension level of students like short stories, riddles, fables and legends show no significant relationship using the quarterly assessment.

The findings using this measure asserted that when students are provided with the mother tongue, they can easily and better understand the message of the parables. The hidden message and meaning of the parables seemed difficult for the students to understand. In addition, most of the instruments used to measure the achievement level of the students and the comprehension level yield a score that established a positive relationship.

These findings implied that the pupils achieved very satisfactory level of comprehension and achievement because they are proficient in L1. Mother tongue plays a significant role in making learning possible. Learning in this sense requires the pupils not merely the ability to read and write but a critical mind to see through the assumptions or positions hidden in the genre. Pupils' level of vocabulary is an essential variable that play a vital role in the development of comprehension. The student's understanding of the selection can be established if the students are well versed, can communicate effectively, and can understand the basic sight words and vocabulary as provided in the selection.

The findings of this study supported the assertion of the research conducted by McLaughin and DeVoogd (2004) that the learner's L1 make the learners engage in the learning process because comprehension of real messages occurs. When the students are provided with the information that they can easily understand, usually this happens when the learners are familiar with the language used by the teacher, the message can easily be captured by the students.

This scenario is very evident in this research because students tend to better understand the selection when expressed in the language the learner are comfortable with. On a similar note, the findings of this research also support the study of Dutcher (1994) which focuses on mother tongue-based education which asserted that individuals develop literacy skills and master the content of material most easily when they are taught in a familiar language.

The findings of this research emphasized the significant positive relationship of mother tongue using the selected variables that measure the students' achievement. It says that when students are taught using the mother tongue, the easier for the students to understand the content of the lesson, thus increasing the student's level of achievement. Likewise, students become actively involved in the lesson. They tend to communicate well among each other. A good sense of collaboration and interaction in the class is established. This classroom 
scenario is a good measure to establish a good comprehension level and achievement as claimed by the study of Dutcher (1994), and McLaughin and DeVoogd (2004).

Moreover, student's familiarity on the language used by the teacher has a direct relationship with their understanding of content which also helped to establish deep understanding. When the students are not familiar with the language of instruction, they tend to exhibit an attitude of confusion thus affecting their level of accomplishment. Through the use of mother tongue, the students are able to comprehend the content since this is the language they are comfortable and familiar with. This assertion supports the study of Brock-Utne's and Alidou's asserting that pupils in school become more active when familiar language is used in the conduct of the lesson.

Pupils' comprehension is positively related to achievement because of the recognition of words of the text. The comprehension of the concepts and ideas conveyed in the literature can be grasped by the pupils when mother-tongue is also employed by the teacher. Students are able to identify the meaning of the text as a whole and not as a series of sentences or individual words. This enables them to understand the selection. The findings of this research supported in general the literature which consistently asserted that the construction of a coherent representation of the text is central to the success of the comprehension of the pupils.

Using the different tools to measure the literary level and comprehension of the students, the study claims the significant relationship between the two variables. Pupils tend to develop cognitive literacy through a better understanding of the concept presented in the literary selection. Thus, this cognitive process which is directly related to the comprehension level and achievement of the students leads to the accomplishment of their educational goals. This finding supports the study of Anderson and Krathwohl (2001).

The data in this study also revealed that the comprehension level of the students is directly related to the academic achievement. Using the different literary selections, it was found out that when students were not able to understand the context of the selection, they tend to exhibit a low score. For instance, in the provided examinations for parables and fables, the students got low scores primarily due to the difficulty of understanding the wordings and the meaning of the selection provided.

The study also asserted that when there was a better understanding of the concept, the higher will be the assessment of the pupils. The level of pupils' understanding of the selection is a key element in increasing the achievement level of the pupils. Although teaching practices were not closely examined as a variable in the study, students manifest a good level of achievement on the examinations given because the teacher uses a familiar language in which students are proficient.

This is identical with the result of the study of Alidou (1997) which he asserted that learning outcomes were observed in classes where a familiar language in which students and teachers are proficient was used. Students manifested a better understanding of the poems even with the use of words that are not commonly used in the ordinary communication but because these words were expressed in their mother-tongue.

The students were able to comprehend their meaning. In this context, the students are able to understand the meaning of the selection. Students became active in the class discussion when they are comfortable to share their thoughts using a language that they are familiar. However, pupils became timid and shy and worst lacks motivation to actively participate in the discussion if they have limited vocabulary to express their thoughts; if a foreign language is used in the facility of the lesson. This adversely affects the level of their performance and the level of their achievement.

The use of riddles expressed in the mother tongue resulted to the high achievement level of the students. Those pupils, however, who are not aware of the riddles even when express in mother tongue still experience difficulty. The study reveals that the familiarity of the riddles that were expressed in the foreign language or in mother tongue is needed for the learners to establish a good level of comprehension. The level of the pupils' achievement and comprehension in short stories shows a positive relationship using the PHIL-IRI and report card but no significant relationship using the quarterly assessment. This means that the comprehension level of the students using the standards set by the department of education proved the significant relationship. When the students were provided with different activities and with the facility of a familiar language, the students 
tend to better understand the selection. This means that the teacher should aid the students with the better way of using the mother tongue in the development of the pupils' comprehension to achieve desirable literary achievement.

The pupils' comprehension and level of literary achievement using fables and legends almost yield the same results. Using the PHIL-IRI and report card, the achievement level in the literary selection and the comprehension level are significantly related with each other. Although the study proved that there is no significant relationship with the literary achievement using the quarterly assessment, the use of mother tongue proved its usefulness during the facility of the lesson. The score obtained by the students, although did not necessarily reached the desirable score to reach the level of significance, still proved that mother tongue is a helpful language to understand the content of the selection.

During the facility of the lesson and when the teacher used the mother-tongue the learners were able to participate actively. They tend to express their thoughts not only on the content of the legends and fables, but also on the context where these literary selections were drawn. This means that students were more likely to actively participate in the classroom discussion and help them to understand to achieve such level of literary achievement. The findings of this study proved that the used of standardized measure of pupils' comprehension and level of literary achievement yielded a positive relationship. For instance, the results of the quarterly assessment of short stories, fables and legends yielded a consistent level of 0.09 thereby accepting the null hypothesis that statistically meant that there is no significant relationship between the level of literary achievement and the pupils' level of comprehension. The same was true with riddles although yielded a different result of 0.07 value.

It can be reflected that because the quarterly assessment is not merely a standardized test compared to the report card achievement which is based on the standard measure of the pupils' level of achievement, a significant relationship between the two variables could not be established. However, the PHIL-IRI being a standardized measure for pupils' comprehension proved that the level of literary achievement is significantly related to one another. The data in this table proved consistently that using the different literary selections, when the standardized measure is used to determine the achievement level of students, the level of comprehension and achievement in the literary genre relates to each other. Although the quarterly assessment being prepared by the teacher in accordance with the performance and content standards set by the DepEd, such measure is not standardized. This assessment may not be considered as standardized assessment, thus proved that there is no significant relationship between the variables measured.

\section{Summary, Conclusion, and Recommendation}

This section presents the brief summary of the previous sections and its findings. It also contains the conclusions and recommendations formulated based on the findings of the study.

\subsection{Summary of Findings}

From the data gathered, analysed and interpreted, the following findings were presented in summary format.

a. The Level of Comprehension of the Grade 3 Pupils

The Grade III pupils achieved very satisfactory level of comprehension in terms of poems with a mean score of 8.41 ; short stories that obtained the mean score of 7.85 ; riddles mean score of 7.54; parables with a mean of 8.30; and legends which obtained the mean of 7.13 
On the other hand the pupils have satisfactory level of comprehension in fables which obtained the mean of 5.99 .

b. In Terms of the Achievement of the Grade 3 Pupils in the Following Assessment Tools Integrating Mother Tongue as Medium of Instruction:

\section{In Terms of PHIL-IRI}

The Grade 3 pupils have achieved the very satisfactory achievement in PHIL-IRI with a mean score of 9.91 as an assessment tool integrating mother tongue as medium of instruction.

\section{In Terms of Quarterly Assessment}

In terms of quarterly assessment integrating mother tongue as medium of instruction the Grade III pupils achieved the very satisfactory level of achievement since it obtained the mean score of 27.37

\section{In Terms of Grades in the Report Card}

The Grade 3 pupils have satisfactory level of achievement in the report cards as an assessment tool integrating mother tongue as medium of instruction because it obtained a mean score of 82.98 .

c. In Terms of Significant Relationship Between the Level of Comprehension and in the Literary Achievement of Grade 3 Pupils:

The pupils' achievement in question no. 3 is significantly related to all the pupils level in PHIL-IRI as reflected in the $r$ value of 0.56 and a p-value of $0.000^{* *}$ and thereby rejecting the hypothesis.

Secondly, the poems achievement and PHIL-IRI, quarterly assessment and report cards; parables achievement and PHIL-IRI, quarterly assessment and report cards; riddles achievement and PHIL-IRI and report card; fables achievement versus PHIL-IRI and report cards; legends achievement and PHIL-IRI and report card have high significant relationships.

\subsection{Conclusion}

Based on the findings of this current study, the researchers present the following conclusions:

a. The Grade 3 pupils comprehend in a very satisfactory level in the literary genres because they are written and presented in their mother tongue.

b. The pupils' gained very satisfactory level of achievement in terms of poems, short stories, riddles, parables, legends and satisfactory level of comprehension in fables. They also achieved very satisfactory level of achievement in PHIL-IRI, Quarterly Assessment and satisfactory level in the Report Cards.

c. There is a high significant relationship between the level of comprehension and in the literary achievement of Grade 3 pupils integrating mother tongue as medium of instruction where they are very proficient of. 


\subsection{Recommendations}

The following recommendations were formulated:

a. Teachers must provide more reading materials for pupils in order to motivate them to undergo reading most of the time to attain an outstanding level of comprehension in the literary genres.

b. Teachers should find ways or strategies on how to uplift the performance output of the pupils in order to achieve very satisfactory or outstanding grades in the report cards.

c. School heads should constantly conduct seminars, technical assistance and monitoring and evaluation on both teachers and pupils in accordance to DepEd Orders about the use of mother tongue as medium of instruction in the primary grades.

d. Future researchers may conduct studies focusing on other variables and circumstances affecting the comprehension, development, and performance of pupils in school through L1.

\section{References}

Books:

Herald, K., General Interest Periodicals-Korea Copyright Financial Times Information Limited (Jan 19, 2002)

Smith, P. J., et al. Tongue and Mother Tongue (Number 10)

The Black Scholar (2003) Volume 33; page 5

Young, Catherine; et al. Mother Tongue-Based Multilingual

Education: Guide for Teacher Educators and Students. (2016)

Alcudia, F. L., et al. Mother Tongue: for Teaching and Learning (2016)

Published Materials:

Black, R. How is a Purposive Sampling becomes a non- probability sampling? (2010)

Hitotuzi, N. The Learner's Mother Tongue in the L2 learning-Teaching Symbiosis. Profile, 7(1), 161-171.

(1992)

Gerente, E. Ideologies of language and schooling in guinea-conakry: An exploratory study of teachers' perspectives about mother -tongue education. (2003)

Jump-up (Puffin). An Anthology of Black Poetry (1990)

Stone, P. A professional development program for the mother tongue-based teacher: Addressing teacher knowledge and attitudes about MTBMLE. (2012) Tomasulo \& Pawelski. Parables: How to Live A Morally Upstanding Life, through God's Words and Teachings. (2012)

Wood, D. How Children Think and Learn (2 $2^{\text {nd }}$ edition)

Oxford: Blackwell. Publishing. (2001)

\section{Unpublished Material:}

Arzadon, C. Starting Where the Children Are: A Collection of Essays on Mother Tongue-Based Multilingual Education and language Issues in the Philippines. (2010)

Dutcher, C. Mother Tongue-based Education: Develop Literacy Skills. (1994)

Gold, J. \& Gibson, A Reading Aloud to Build Comprehension/Reading Rockets. (2001)

Hadaway, Vardell and Young. Rhyming Words: Key to learn new words.(2001)

Hall, J. Appropriate Materials:Established Government Curriculum goals, culture and system. (2010)

Keleman, A. Fables creating a degree of complexity for the kids' understanding. (2014) 
Malone, S. Mother Tongue-based multilingual education: Implications for education policy. SIL International. (2007)

McLaughin \& Devoogd. Language 1: Engages one to the comprehension of real messages. (2004)

Needlman, R.Reading aloud/Strategies to engage students as readers.(2004)

Nolasco. Multilingual Education: The Achievement of the MillenniumDevelopment Goals and "Education for All." (2010)

Oyzon, V. Q. Taking Another Woman as my Mother: The State of Waray Language as Used by Today's Waray Children. ( 2012)

Rog, Retelling as an effective reading comprehension strategy for younggeneration. (2001)

Sunday \& Joshua, Teaching and Learning Needs Adequate and Relevant Use of Instructional Materials. (2010).

Journal

Dekker, D. E., A case study of the first language component bridging program in rural Philippines. Philippine Journal of Linguistics, 143-149

Sanchez, A., Journal of International Education Research, 2013

Lartec, J., et al; The IAFOR Journal of Language Learning, 2014

Ganal, N., Indian Journal of Management Science (IJMS), 2014

Ngaka, W., Masagazi, F., Journal of Language and Literacy Education, v11 n1 p88-108 Spr 2015

Quiroz, B. and Quintin, D.Dixon, Journal of Early Childhood Literacy, v12 n2 p139-175 (Jun 2012)

Young, C. First Language: A foundation for effective basic education. Philippine Journal of Linguistics, 34 (1), 123-131, (2003)

Online References

Aslan, Canan, Online Submission, Paper presented at the International Educational Technology (IETC) Conference 7th, Nicosia, Turkish Republic of Northern Cyprus, (May 3-5, 2007)

Akello, D. L., et. al. Language and Education, v30 n3 p252-266, (2016)

Bingayen, R.A. (2013). Starting where the children are: A collection of essays on Mother Tongue-Based Multilingual education and Language issues in the Philippines.http://iteachilearn.com/cummins/mother.htm

Cummins, J. (2000). Bilingual Children's Mother Tongue: Why is it important for education. http://iteachilearn.com/cummins/mother.htm

Kenpro (2010). Theories of Language Development in Children. http://www.kenpro.org/papers/theories-of-language

Malone, S. (2010). Guide to Developing a "Sounds of our Language." http://www.sil.org/acpub/repository/MLE\%20Planning\%20man.pdf

Pelletier, L.(2003). Children's Understanding of Aesop's Fables: Relations to Reading Comprehension and Theory of Mind.https.//www.ncbi.nlm.nih.gov/pmc/articles

Pinnock, H. (2009). Language and Education: the missing link http:unesco.org/education/EFAWG2009/LanguageEducation.pdf

Krashen, S. (2001). Principles and Practice of Language Acquisition. http://www.languageimpact.com/articles/rw/krashenbk.htm

Thomas, W. P. \& Collier, V. P. (1997). School effectiveness for language Minority students. http://www.ncela.gwu.edu/ncbepubs/resourse 
